\title{
О СКОРОСТИ СЕДИМЕНТАЦИИ В БАЛТИЙКОМ МОРЕ ПО ДАННЫМ ИЗУЧЕНИЯ МОЩНОСТИ ДОННЫХ ОСАДКОВ
}

Седиментация в Балтийском море характеризуется накоплением терригенного материала. Влияние биогенных и хемогенных продуктов на осадкообразование небольшое. По материалам многих исследователей (Блажчишин и др., 1970; Стелле и др., 1976; Хомутова, 1977; Кессел, 1980 и др.), мощность голоценовых осадков редко превышает 3-4 м. Скорость терригенной седиментации, расчитанная А. И. Блажчишиным (1972) по объему поступающего в море кластического материала, составляет для всего моря в среднем 0,056 мм/год, в глубоководных седиментационных областях 0,075 мм/год и в прибрежных 0,21 мм/год Максимальные скорости седиментации отмечены в Курсшком заливе 0,33 мм/год, минимальные - в Ботническом заливе - 0,014 мм/год. О. С. Пустельниковым (1977) определена скорость современного осадкообразования в Балтике путем изучения взвешенного материала. По его расчетам она составляет для всего моря в среднем 0,079 мм/год, а для глубоководных зон седиментации 0,14 мм/год. Эти показатели дают представление о темпе и масштабах современного осадконакопления в Балтийском море. Данных о скорости осадконакопления в течение всего голоцена, а также по отдельным стадиям развития Балтики, практически не имеется.

Хотя за последние $10-15$ лет из различных частей Балтики отобрано большое количество колонок донных осадков, до сих пор мало таких, в которых точно и уверенно выделяются осадки, накопившиеся в течение разных стадий развития моря. В настоящем сообщении сделана попытка дать приблизительное представление о скорости осадконакопления в Балтийском море в голоцене в целом и по стадиалам. Приведенные сведения основываются на материалах, собранных автором по Вяйнамери и другими исследователями по прочим частям Балтийского моря (Кессел и др., 1973; Стелле и др., 1976; Кессел, 1980).

Таблица 1

Распределение мощностей (числитель) (см) и скоростей осадконакопления (знаменатель) (мм/год) по стадиалам в Вяйнамери

\begin{tabular}{|c|c|c|c|c|c|}
\hline \multirow{2}{*}{ Стадиал } & \multicolumn{5}{|c|}{ Номер колонки и глубина ее (в скобках), $\mu$} \\
\hline & $17(7,8)$ & $28(3,3)$ & $43(14,2)$ & $128(2,7)$ & $171(0,8)$ \\
\hline $\begin{array}{l}\text { SA } \\
\text { SB } \\
\text { AT } \\
\text { BO }\end{array}$ & $\begin{array}{l}13 / 0,046 \\
11 \%, 055 \\
12 \%, 04 \\
41 \%, 32\end{array}$ & $\begin{array}{c}11 \%, 0,039 \\
8 \%, 04 \\
7 \% 0,023 \\
26 \%, 20\end{array}$ & $\begin{array}{l}17 / 0,061 \\
20 \%, 1 \\
20 \%, 15\end{array}$ & $\begin{array}{l}32 / 0,11 \\
31 \% 0,16 \\
40 \% 0,13\end{array}$ & $\begin{array}{l}50 \%, 18 \\
30 \%, 15 \\
50 \%, 17 \\
17 \%, 13\end{array}$ \\
\hline $\begin{array}{c}\text { Весь го- } \\
\text { лоцен }\end{array}$ & $77 / 0,08$ & $68 / 0,07$ & $61 / 0,06$ & $108 / 0,10$ & $149 / 0,15$ \\
\hline
\end{tabular}

3 ENSV TA Toimetised. G 21982 


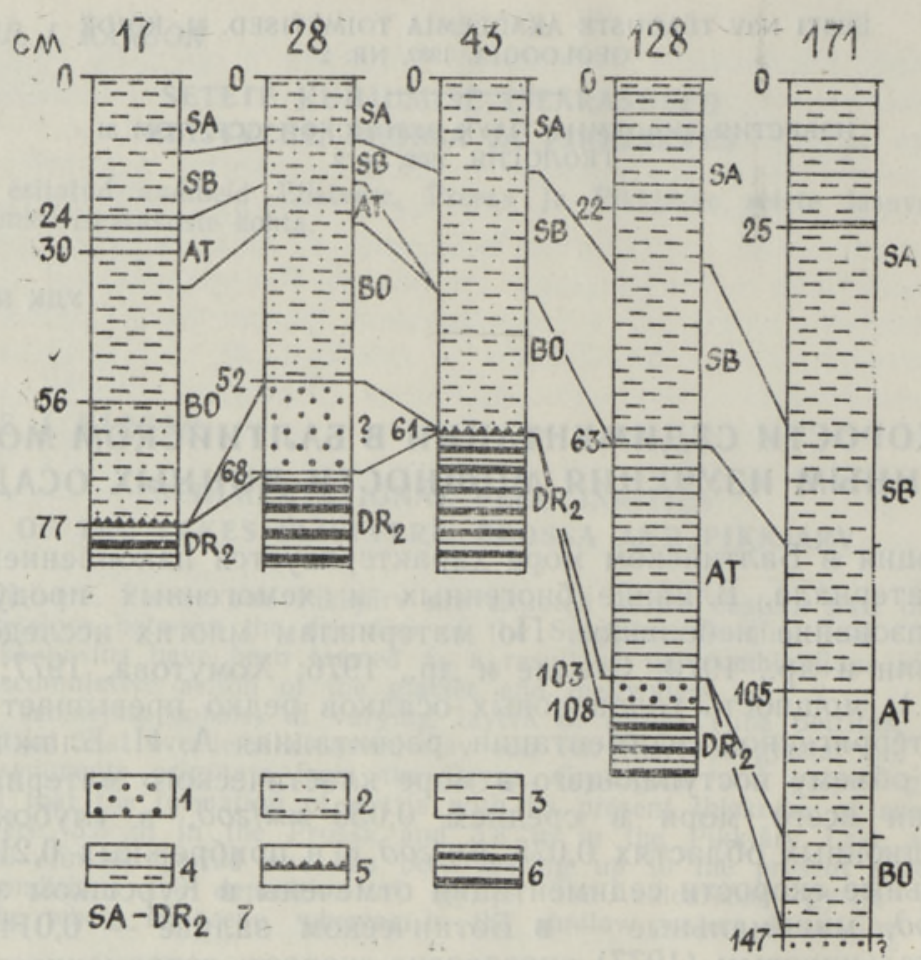

Стратиграфическое расчленение донных осадков Вяйнамери (анализы провела Х. Кессел). 1 - песок, 2 - крупный алеврит, 3 - мелкий алеврит, 4 - алевритово-пелитовый нл, 5 - базальный слой, 6 - ленточная глина, 7 - зоны развития растительности (по К. Каяку и др., 1976).

В результате палинологического изучения донных осадков, выполненного Х. Кессел, в Вяйнамери четко выделяются поздне- и послеледниковые (голоценовые) отложения. Первые представлены ленточными глинами, которые вскрываются во многих скважинах и обнажаются нередко на подводном береговом склоне. Голоцен представлен осадками бореального (BO), атлантического (AT), суббореального (SB) и субатлантического (SA) стадиалов (рисунок). До сих пор нет основания выделять пребореальные (РВ) донные осадки.

Бореальные донные осадки, или осадки Анцилового озера мощностью от 17 до $41 \mathrm{~cm}$, образовавшиеся в течение 1300 лет (от 9100 до 7800 лет назад), вскрытые колонками 17, 28, 43 и 171 (табл. 1), представлены алевритом или алевритово-пелитовым илом (рисунок). Исходя из данных о мощностях бореальных осадков можно сказать, что скорость накопления седиментационного материала во время этого стадиала изменяется от $0,13 \mathrm{mм} /$ год в колонке 171 до 0,2 мм/год в колонке 17 (табл. 1).*

Атлантические донные осадки, или осадки Литоринового моря мощностью от 7 до 50 см, образовавшиеся в течение 3000 лет (от 7800 до 4800 лет назад), представлены алевритом, реже пелитовым илом (рисунок). Скорость накопления седиментационного материала колеблется от 0,023 до 0,17 мм/год (табл. 1).

Суббореальные донные осадки мощностью от 8 до 31 cм, образовавшиеся в течение 2000 лет (от 4800 до 2800 лет назад), во всех

\footnotetext{
* Здесь и в дальнейшем не учитывается естественное уплотнение осадков в ходе начальных этапов диагенеза.
} 
колонках (табл. 1) представлены мелким или крупным алевритом (рисунок). Накопление седиментационного материала происходило со скоростью от 0,04 мм/год в колонке 28 до 0,16 мм/год в колонке 128 (табл. 1).

Субатлантические донные осадки, образовавшиеся в Лимниевом море в течение последних 2800 лет, вскрыты также всеми приведенными колонками. Их мощность колеблется от 11 до $50 \mathrm{~cm}$ (табл. 1). Осадки этого стадиала представлены крупным и мелким алевритом или алевритово-пелитовым илом (рисунок). Скорость накопления осадков колеблется от 0,039 до 0,18 мм/год (табл. 1).

Средняя скорость осадконакопления в течение голоцена (последние 10200 лет) в Вяйнамери, по изучению материала этих колонок, колеблется от 0,06 до 0,15 мм/год, однако последнюю цифру не следует считать для этого бассейна предельной. Так, в наиболее глубокой части Вяйнамери, в проливе Суур-Вяйн, где глубина воды достигает 22,6 , нами отобрана колонка голоценовых крупных алевритов длиной $220 \mathrm{~cm}$, по которой скорость накопления голоценовых осадков составляет более $0,22 \mathrm{MM} /$ год.

Данные по открытым частям Балтики и Рижскому заливу приводятся по материалам Х. Кессел с соавторами (Кессел и др., 1973; Кессел, 1980).

Пребореальные донные осадки вскрыты колонкой 2208 из Эландской впадины с глубины 138 м и колонкой 4 из залива Аристе с глубины 26,5 м. Они имеют мощность 242 cм (табл. 2) и представлены серой глиной и темно-серым пелитовым илом (Кессел и др., 1973). В колонке 4 мощность пребореальных алевритовых осадков составляет 80 см (Кессел, 1980). По данным Х. Кессел, скорость пребореального осадконакопления составляет 2,2 мм/год в Эландской впадине и 0,73 мм/год в заливе Аристе (табл. 2).

Таблица 2

Распределение мощностей (числитель) (см) и скоростей осадконакопления (знаменатель) (мм/год) в открытых частях Балтийского моря и в Рижском заливе

\begin{tabular}{|c|c|c|c|c|c|c|c|}
\hline \multirow[b]{3}{*}{ Стадиал } & \multicolumn{7}{|c|}{ Номер колонки и глубина ее (в скобках), м } \\
\hline & $1465(47)$ & $1457(41)$ & $2208(138)$ & $2119(173)$ & $1729(132)$ & $9(54)$ & $4(26,5)$ \\
\hline & $\begin{array}{l}\text { Аркон- } \\
\text { ская } \\
\text { впадина }\end{array}$ & $\begin{array}{c}\text { Борн- } \\
\text { хольм- } \\
\text { ская } \\
\text { впадина }\end{array}$ & $\begin{array}{c}\text { Эланд- } \\
\text { ская } \\
\text { впадина }\end{array}$ & $\begin{array}{c}\text { Восточ- } \\
\text { ногот- } \\
\text { ландская } \\
\text { впаднна }\end{array}$ & $\begin{array}{c}\text { Финский } \\
\text { залив }\end{array}$ & $\begin{array}{c}\text { Рижский } \\
\text { залив }\end{array}$ & $\begin{array}{r}\text { залив } \\
\text { Аристе }\end{array}$ \\
\hline $\begin{array}{l}\text { SA } \\
\text { SB } \\
\text { AT } \\
\text { BO } \\
\text { PB } \\
\end{array}$ & $\begin{array}{l}20 \%, 071 \\
85 \% 0,42 \\
30 \%, 0,1 \\
22 \%, 17\end{array}$ & $\begin{array}{l}60 / 0,21 \\
91 / 0,46\end{array}$ & $23 / 0,082$ & $\begin{array}{l}20 \%, 071 \\
30 \%, 15 \\
150 \%, 5\end{array}$ & $314 / 1,12$ & $\begin{array}{l}170 \% 0,61 \\
150 \%, 75 \\
60 \%, 0,2 \\
60 \%, 46\end{array}$ & $\begin{array}{c}170 / 1,3 \\
80 \%, 73\end{array}$ \\
\hline $\begin{array}{c}\text { Весь го- } \\
\text { лоцен }\end{array}$ & $157 / 0,15$ & $151 / 0,15$ & $267 / 0,26$ & $200 \%, 2$ & $314 / 0,31$ & $440 \%, 43$ & $310 \%$ \\
\hline
\end{tabular}

Бореальные донные осадки вскрыты в Арконской впадине колонкой 1465 мощностью $22 \mathrm{~cm}$, колонкой 9 в Рижском заливе мощностью 60 см и колонкой 4 в заливе Аристе западнее о-ва Сааремаа мощностью $170 \mathrm{~cm}$ (табл. 2). Они представлены серым алевритом. Скорость их накопления соответственно $0,17,0,46$ и 1,3 мм/год.

Атлантические донные осадки, представленные пелитовым илом (колонка 1465), глиной (колонка 2119) и алевритом (колонка 9), различной мощности накапливались со скоростью $0,1-0,5$ мм/год (табл. 2). 
Суббореальные пелйтовые илы, вскрытые в Арконской, Б̈орнхольмской и Восточно-Готландской впадинах, имеют мощность $30-91$ cm. В колонке из Рижского залива суббореал представлен алевритом мощностью 150 см. Скорость накопления этих осадков колеблется от 0,15 мм/год в Восточно-Готландской впадине до 0,75 мм/год в Рижском заливе (табл. 2).

Субатлантические донные осадки впадин представлены пелитовым или алевритово-пелитовым илом мощностью 20-60 cм. В колонке 1729 , взятой в устьевой части Финского залива, мощность субатлантических темных илов значительно болыше - 314 cм (Кессел, и др., 1973). В Рижском заливе мощность субатлантических алевритов также значительная - 170 см. В заливе Аристе субатлантические осадки мощностью 60 см представлены в основном пес́ком (Кессел, 1980). Скорость накопления седиментационного материала в субатлантическом стадиале в изученных впадинах $0,071-0,21$ м.м/год. Более значительна она в Рижском заливе - 0,61 мм/год, и особенно в устьевой части Финского залива - 1,12 мм/год. Пески залива Аристе накапливались со скоростью $0,21 \mathrm{м \mu /год.}$

Данные по Юго-Восточной части Балтики (табл. 3) приводятся по материалам В. Я. Стелле (Стелле и др., 1976). Эти колонки, взятые с глубин 42-145 $м$, характеризуются полнотой разреза голоценовых осадков, чего нельзя сказать о колонках из других частей моря (табл. 2 и 3$)$.

Таб́лица 3

Распределение мощностей (числитель) (cм) и скоростей осадконакопления (знаменатель) (мм/год) в Юго-Восточной Балтике

\begin{tabular}{|c|c|c|c|c|c|c|}
\hline \multirow{2}{*}{ Стадиал } & \multicolumn{6}{|c|}{ Номер колонки } \\
\hline & 132 & 245 & 375 & 398 & 163 & 255 \\
\hline $\begin{array}{l}\text { SA } \\
\text { SB } \\
\text { AT } \\
\text { BO } \\
\text { PB }\end{array}$ & $\begin{array}{l}15 / 0,054 \\
10 \% 0,05 \\
50 \% 0,17 \\
90 \% 0,69 \\
15 \% 0,14\end{array}$ & $\begin{array}{l}25 / 0,089 \\
10 \% 0,05 \\
45 / 0,15 \\
20 \% 0,15 \\
15 / 0,14\end{array}$ & $\begin{array}{l}30 / 0,11 \\
10 \% 0,05 \\
28 / 0,093 \\
28 / 0,22 \\
30 \% 0,27\end{array}$ & $\begin{array}{l}40 / 0,14 \\
10 \% 0,05 \\
50 \% 0,17 \\
90 \% 0,69 \\
15 \% 0,14\end{array}$ & $\begin{array}{c}55 / 0,2 \\
20 \% 0,1 \\
55 / 0,18 \\
145 / 1,12 \\
75 \% 0,68\end{array}$ & $\begin{array}{l}15 / 0,054 \\
10 \% 0,05 \\
50 \% 0,17 \\
30 \% 0,23 \\
10 \% 0,09\end{array}$ \\
\hline Весь голоцен & $180 / 0,18$ & $115 / 0,11$ & $126 / 0,12$ & $205 / 0,2$ & $350 / 0,34$ & $115 / 0,11$ \\
\hline
\end{tabular}

Представленный материал показывает, что скорость осадконакопления неодинакова в разных частях Балтики, а также по отдельным стадиалам. Даже в пределах небольшого и мелководного Вяйнамери по темпам осадконакопления можно выделить два типа разрезов. К первому типу относятся разрезы 17,28 и 43, по которым скорость осадконакопления в субатлантическом, суббореальном и атлантическом стадиалах заметно уступает скорости осадконакопления в бореальном стадиале. Ко второму типу относятся разрезы 128 и 171 с более или менее равномерной скоростью осадконакопления по всем выявленным стадиалам.

Изменчивость скорости осадконакопления по стадиалам в открытых частях моря еще более значительна. Материалы Х. Кессел и соавторов (Кессел и др., 1973; Кессел, 1980) свидетельствуют о том, что голоценовое осадконакопление в Балтике изменчивое и прерывистое. В то же время данные В. Я. Стелле и соавторов (Стелле и др., 1976) показывают, что осадконакопление шло, по крайней мере, в юговосточной части моря непрерывно. Из табл. 2 явствует, что в пребореале и бореале наблюдалось осадконакопление лишь в некоторых 
частях моря, причем интенсивность его была для Балтики высокой. Более широко распространены осадки атлантического, суббореального и субатлантического стадиалов, но скорость их накопления заметно меньше. Судя по колонке 9, осадконакопление в глубоководной части Рижского залива началось в бореале. Начиная с этого времени можно говорить об относительно постоянном быстром темпе накопления осадочного материала. По-видимому, полузакрытый Рижский залив можно рассматривать как своеобразный уловитель седиментационного материала.

Сведения о скорости осадконакопления в Балтийском море малочисленны и отчасти противоречивы. По мнению ряда исследователей (Стелле и др., 1976), голоценовый разрез Балтики полный, по мнению других (Кессел и др., 1973; Кессел, 1980), наоборот, неполный. Иногда данные противоречивы даже по одной и той же, или, по крайней мере очень близко расположенным колонкам (например, интерпретация колонки 2119 В. И. Хомутовой (1977) и Х. Кессел (Кессел и др., 1973)). Исследователю, не занимающемуся непосредственно палинологической работой, прудно понять суть таких расхождений.

Проанализированные данные показывают, что мощность осадков, а следовательно, и темп накопления седиментационного материала в разных частях Балтики в голоцене очень сильно колеблются. Средняя скорость седиментации в голоцене (табл. 1-3), как правило, значительно выше темпа осадконакопления на современном этапе, рассчитанного по объему поступающего в море кластического материала (Блажчишин, 1972) или по результатам изучения распределения взвеси (Пустельников, 1977). Прерывистость разрезов, а нередко и присутствие в разрезе лишь наиболее молодых, субатлантических осадков показывает, что относительно большое значение имеет в Балтике перераспределение осадочного материала. В общих чертах наши расчеты показывают, что современное (resp. атлантическое) время характеризуется некоторым уменьшением темпа осадконакопления по сравнению с более ранними этапами седиментации.

\section{Л И ТЕ РА Т У Р А}

Бл а жчишин А. И. Геологическое строение и донные осадки Балтийского моря. Автореф. дис. канд. геол.-мин. н. Калининград, 1972.

Блажчишин А. И., Литвин В. М., Лукошявичус Л., Руденко М. В. Новые данные по рельефу дна и строению осадочной толщи центральной части Балтийского моря. - Балтика, 1970, 4, 145-168.

К аяк К., Кессел Х., Лийвранд Э. и др. Местная стратиграфическая схема четвертичных отложений Прибалтики. Вильнюс, 1976, $4-52$.

Кессел X. Возраст донных отложений Балтийского моря в Западно-Эстонском архипелаге по палинологическим данным. - Изв. АН ЭССР. Геол., 1980, 29, $17-23$.

Кессел Х., Давыдов а Н., Блажчишин А. Пыльца и диатомовые из колонок глубоководных впадин Балтики. - Изв. АН ЭССР. Хим. Геол., 1973, 22, $345-354$

Пустельников О. С. Баланс осадочного материала и скорости современного осадкообразования в Балтийском море (по данным изучения взвеси). Балтика, $1977,6,155-160$.

Стелле В. Я., Авдеева-Феодосеева И. Я., Ефимов А. И., Савваи . тов А. С. Палиностратиграфия донных осадков юго-восточной части Балтийского моря. - В кн.: Палинология в континентальных и морских геологических исследованиях. Рига, 1976, 102-118.

Хомутов а В. И. Палинологическая характеристика послеледниковых донных отложений центральных и юго-восточных районов Балтийского моря. - Балтика, $1977,6,17-31$.

Ннститут геологии

Академии наук Эстонской ССР
Поступила в редакцию I/IX 1981 


\section{SETETE KUHJUMISE KIIRUSEST LÄANEMERES POHJASETETE PAKSUSE ALUSEL}

Artiklis on antud lühiülevaade setete kuhjumise kiirusest Läänemeres holotseeni vältel (aluseks põhjasetete paksus). Lähteandmetena on kasutatud autori poolt Väinamerest kogutud stratigraafilist materjali, samuti Läänemere eri piirkondades töötanud uurijate töid.

Joldiamere ja Antsülusjärve setteid on ulatuslikumalt Läänemere lõunaosas, nende kuhjumine on olnud suhteliselt intensiivne. Tunduvalt laiema levikuga on Litoriinamere ja eriti Limneamere setted, kuid nende kuhjumise kiirus on mõnevõrra väiksem.

Toodud materjali põhjal on järeldatud, et Läänemeres on holotseeni setete kuhjumise kiirus olnud piirkonniti erinev - 0,06 mm/a. Väinameres kuni $0,43 \mathrm{~mm} / \mathrm{a}$. Riia lahes. Kliimastaadiumide kaupa on andmed järgmised: preboreaalne kliimastaadium $0,09-2,2 \mathrm{~mm} / \mathrm{a}$., boreaalne $0,13-1,3$, atlantiline $0,023-0,5$, subboreaalne $0,04-0,75 \mathrm{ja}$ subatlantiline $0,039-1,12 \mathrm{~mm} / \mathrm{a}$.

\section{J. LUTT}

\section{VELOCITY OF ACCUMULATION OF SEDIMENTS IN THE BALTIC SEA ON THE BASIS OF THE THICKNESS OF BOTTOM SEDIMENTS}

The author presents a survey of the velocity of sediment accumulation in the Baltic Sea during the Holocene (as based on the thickness of bottom sediments), using stratigraphical materials collected by himself in the Väinameri as well as data on different parts of the Baltic, accumulated by other researchers.

The sediments of the Yoldia Sea and Ancylus Lake are most abundant in the southern part of the Baltic, where their accumulation was rather intensive. The Littorina Sea sediments, and particularly those of the Limnean Sea, have been of a much wider distribution, but of a somewhat lesser rate of accumulation.

On the basis of available material it has been concluded that the rate of accumulation of Holocene sediments in the Baltic has been varying in different regions, from $0.06 \mathrm{~mm} /$ year in the Väinameri to $0.43 \mathrm{~mm} /$ year in the Gulf of Riga. According to climate stages, the data are as follows: in the Preboreal $0.09-2.2 \mathrm{~mm} / \mathrm{year}$, in the Boreal $0.13-1.3$, in the Atlantic $0.023-0,5$, in the Subboreal $0.04-0.75$ and in the Subatlantic $0.039-1.12 \mathrm{~mm} /$ year. 